\title{
$a^{\text {RRATUM }}$
}

Erratum to the article by E. Andersson Strand, K.M. Frei, M. Gleba, U. Mannering, M.-L. Nosch and I. Skals, 2010. Old textiles - new possibilities. European Journal of Archaeology 13(2), 149—173 (DOI: 10.1177/1461957110365513).

In the above article, on page 164, the Figure 4 as printed is incorrect and should be replaced by the correct Figure 4 as below:

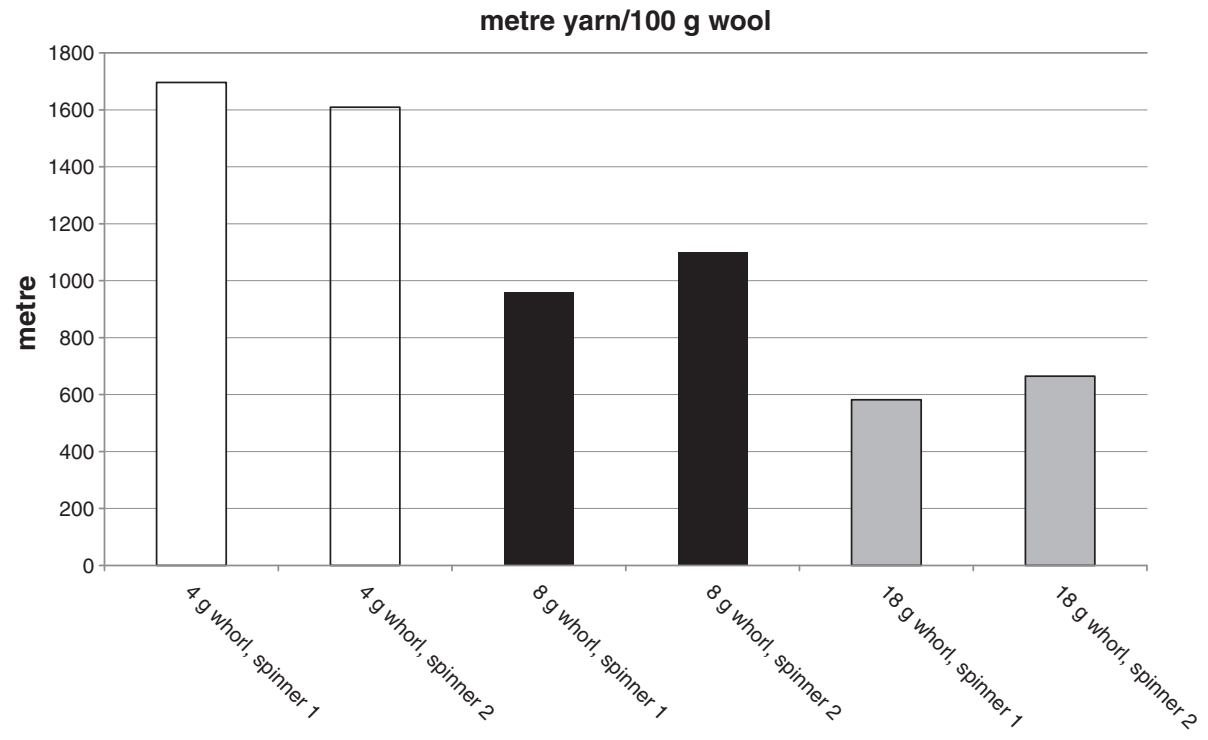

Figure 4. Calculation of metre of yarn per $100 \mathrm{~g}$ spun wool, $4 \mathrm{~g}, 8 \mathrm{~g}$, and $18 \mathrm{~g}$ whorls. 